\title{
A interface estudos discursivos e estudos ergológicos
}

\author{
The interface between discursive studies and ergologic studies
}

\author{
M. Cecília Pérez de Souza-e-Silva \\ Pontifícia Universidade Católica de São Paulo / CNPq - São Paulo - São Paulo - Brasil
}

\begin{abstract}
Resumo: Este artigo tem por objetivo explicitar caminhos teórico-metodológicos aos quais temos recorrido a fim de consolidar o estudo das relações linguagem/trabalho, mais especificamente dos estudos discursivos e ergológicos. Adotar a perspectiva discursiva implica considerar a língua não como instrumento informacional, transparente, mas como polissêmica e opaca. Implica também aceitar que a discursividade define uma ordem própria diversa da materialidade da linguagem, mas que se realiza na língua. Compartilhar a abordagem ergológica significa pensar a atividade de trabalho como o encontro entre as normas e os seres humanos capazes, por suas escolhas, de traduzi-las em cada situação. Ambas as abordagens encontram abrigo no paradigma indiciário, que supõe a existência de um rigor flexível e elástico. Flexível porque não exige o estabelecimento de uma verdade única, universal e inquestionável; elástico porque não prescinde do rigor, não abre mão da interpretação.
\end{abstract}

Palavras-chave: Perspectiva enunciativo-discursiva; Abordagem ergológica; Prescritos no trabalho; Atividade de trabalho; Práticas de linguagem

\begin{abstract}
This paper aims to describe the theoretical-methodological paths that we have been using in order to consolidate the study of the language/work relations, more specifically, the relations between discursive and ergologic studies. Adopting the enunciation-discourse perspective implies considering language not as an informational, transparent instrument, but as polysemic and opaque. In addition, it implies accepting that discursivity defines its own order, different from the materiality of language, but which is fulfilled in language. Sharing the ergologic approach means thinking of the work activity as the encounter between norms and human beings, capable, due to their choices, of translating them in each situation. Both the discursive and ergologic approaches find shelter in the evidentiary paradigm, which assumes the existence of a flexible and elastic rigor. Flexible because it does not require the establishment of a unique truth, universal and unquestionable; elastic because it does not dispense with rigor and does not relinquish interpretation.
\end{abstract}

Keywords: Enunciation-discourse perspective; Ergologic approach; Prescriptions at work; work activity; Language practices

Este artigo resulta de demanda de alguns pesquisadores interessados em conhecer caminhos teóricometodológicos aos quais temos recorrido a fim de consolidar o estudo das relações entre linguagem e trabalho. Nossa proposta está direcionada para duas vertentes - análise das práticas de linguagem em situação de trabalho e análise de discursos sobre o trabalho - as quais implicam dar visibilidade ao trabalho de diferentes atores sociais por meio da observação e análise de suas atividades e dos discursos que circulam nas diferentes comunidades que os constituem e cujos traços indicam uma certa identidade enunciativa. Identidade esta que possibilita definir algumas categorias de trabalhadores/ atores sociais.

\section{Considerações teóricas}

Articular linguagem e trabalho pressupõe, em nosso caso, partir de uma perspectiva enunciativodiscursiva da linguagem e de uma abordagem ergológica do trabalho. Nessa articulação, algumas questões de trabalho se impõem, entre elas o estudo da atividade de diferentes atores sociais - aí compreendidas as normas, os movimentos de renormalização, a formação dos coletivos 
de trabalho - e o conjunto dos discursos das comunidades profissionais em que tais atores estão inseridos, os quais produzem, fazem circular e se reconhecem em tais discursos.

Adotar a perspectiva enunciativo-discursiva implica considerar a língua não como instrumento informacional, transparente, mas como polissêmica e opaca. Implica também aceitar que a discursividade define uma ordem própria diversa da materialidade da linguagem, mas que se realiza na língua. Implica, ainda, aceitar que a língua tem regras próprias (fonológicas, morfológicas e sintáticas), que são postas a funcionar, de uma forma ou de outra, segundo o processo discursivo de que se trata numa certa conjuntura (POSSENTI, 2004, p. 360). Compartilhar a abordagem ergológica significa pensar o trabalho como atividade humana, entendida como um "impulso de vida e de saúde, sem limite predefinido, que sintetiza, atravessa e liga tudo o que as disciplinas têm representado separadamente: o corpo e o espírito; o individual e o coletivo; o fazer e os valores; o privado e o profissional; o imposto e o desejado, etc." (SCHWARTZ, 2010, p. 19). Significa, ainda, partir do princípio de que toda atividade de trabalho é infinitamente mais complexa do que se pode antecipar porque há um ser humano complexo envolvido em sua realização. Esse olhar sobre a atividade tem por objetivo produzir conhecimentos sobre como vivem as pessoas a fim de melhorar suas condições de trabalho (SCHWARTZ, 1997). No âmbito da perspectiva enunciativo-discursiva, continuamos a nos apoiar, prioritariamente, em Dominique Maingueneau. Retomo algumas noções de sua obra clássica Gênese dos discursos (2008a), mas incorporo outras, fruto de suas pesquisas recentes, reunidas em dois livros publicados no Brasil em 2008b e 2010, respectivamente, Cenas da enunciação e Doze conceitos em Análise do Discurso.

Por que Gênese dos discursos? Trata-se de um modo original de fazer análise do discurso. Originalidade que pode ser vista sob vários ângulos, entre eles, a implementação da ideia de que o interdiscurso precede o discurso e o tratamento do discurso a partir de um sistema de coerções globais.

Tomar como pressuposto o princípio do primado do interdiscurso, isto é, a precedência do interdiscurso sobre o discurso, na visada de Maingueneau ${ }^{1}$, significa postular que a unidade de análise pertinente não é o discurso, mas o espaço de trocas entre dois ou mais discursos. Não se trata de considerar cada discurso como uma identidade fechada, nem de levar em conta o fato de haver dois ou mais discursos em contato, ou de um enunciado ter mais de um sentido ou a presença de várias vozes, trata-se de olhar para o espaço discursivo, constituído de pelo menos dois posicionamentos discursivos mantendo relações fortes.
Gênese dos discursos toma ainda como pressuposto o princípio segundo o qual há uma determinação comum, um mesmo conjunto de princípios, as "coerções semânticas", que regem os textos e as práticas institucionais dos grupos que produzem tais textos, que "a enunciação discursiva ao mesmo tempo supõe e torna possível" (MAINGUENEAU, 2008a, p. 23). Trata-se aqui da problemática da inter-relação entre discurso e instituição, ambos regidos por uma mesma rede de coerções que delimitam o funcionamento e as práticas de um mesmo grupo.

Esses dois princípios não só explicam os demais - a competência discursiva/interdiscursiva, a interincompreensão, as práticas discursivas intersemióticas -, mas também funcionam como um filtro que abrange os vários planos do discurso: a intertextualidade, o vocabulário, os temas, o estatuto do enunciador e do coenunciador, a dêixis enunciativa e o modo de enunciação. Enquanto a interdiscursividade é constitutiva e, portanto, nem sempre deixa marcas na materialidade linguística, a intertextualidade deixa seus rastros por meio do intertexto, entendido como o conjunto de fragmentos efetivamente citados por um discurso e considerados legítimos pelas coerções semânticas de um determinado campo discursivo ${ }^{2}$. O mesmo se dá em relação ao léxico e ao tema. O item lexical em si não constitui uma unidade de análise pertinente, ele pode ser explorado contraditoriamente por diferentes discursos, dependendo do posicionamento discursivo. À semelhança do léxico, a especificidade de um discurso não se define por seus temas, mas depende do posicionamento discursivo ${ }^{3}$.

O estatuto do enunciador e do coenunciador e a dêixis enunciativa vêm sendo trabalhados por Maingueneau no quadro mais amplo daquilo que ele designa como cena de enunciação. Apreender uma situação de discurso como cena de enunciação implica considerá-la do "interior", por meio da situação que a fala pretende definir no movimento mesmo de seu desdobramento. "Um texto não é um conjunto de signos inertes, mas o rastro deixado por um discurso em que a fala é encenada" (MAINGUENEAU, 2001, p. 85).

A cena de enunciação associa três cenas de fala: a cena englobante, a cena genérica e a cenografia. A cena

\footnotetext{
1 Na AD-3, Pêcheux adota a perspectiva segundo a qual uma formação discursiva está sempre dominada pelo interdiscurso. Maingueneau se propõe a ligar, por diferentes vieses, duas problemáticas, a da gênese e a da interdiscursividade, apreendendo de uma só vez o discurso através do interdiscurso

2 O recorte em campos discursivos é uma abstração necessária que deve permitir a abertura de múltiplas redes de trocas.

3 Na publicação de 1984, Maingueneau fala sempre em formações discursivas; já no prefácio à tradução em 2008a, opta por posicionamento. É esta a designação que seguiremos. Mais recentemente, em Cenas de enunciação (2008b), distingue dois grandes tipos de unidades: tópicas e não tópicas e situa, entre as segundas, as formações discursivas.
} 
englobante corresponde ao tipo de discurso, a seu estatuto pragmático. Define o estatuto dos parceiros e certo quadro espaço-temporal, isto é, o lugar e o momento legítimos. Tal cena, no entanto, não é suficiente para especificar as atividades discursivas nas quais se encontram engajados os interlocutores, que se veem confrontados com gêneros de discurso particulares, com rituais sóciolinguageiros que definem as cenas genéricas. $\mathrm{O}$ gênero de discurso implica um contexto específico: papéis, circunstâncias (em particular, um modo de inscrição no espaço e no tempo), um suporte material, uma finalidade, uma organização textual, recursos linguísticos específicos etc. (cf. MAINGUENEAU, 2013, p. 72-76).

Estas duas cenas, englobante e genérica, definem, em conjunto, o espaço estável no interior do qual o enunciado ganha sentido, isto é, o espaço do tipo e do gênero de discurso. Finalmente, a cenografia, é instituída pelo próprio discurso ${ }^{4}$. "A escolha da cenografia não é indiferente: o discurso, desenvolvendo-se a partir de sua cenografia, pretende convencer, instituindo a cena de enunciação que o legitima" (MAINGUENEAU, 2008b, p. 117).

Ainda, segundo o autor, em uma cenografia associamse as figuras do enunciador e dos coenunciadores, uma cronografia (um momento) e uma topografia (um lugar), dos quais pretende originar-se o discurso. Trata-se de três polos indissociáveis. "O discurso impõe sua cenografia, de algum modo, desde o início; mas, de outro lado, é por intermédio de sua própria enunciação que ele poderá legitimar a cenografia que ele impõe" (MAINGUENEAU, 2008b, p. 117).

O discurso se caracteriza ainda por uma "maneira de dizer" específica, um modo de enunciação. As reflexões sobre o modo de enunciação, que aparecem também em germe em Gênese dos discursos, têm sido abordadas, mais recentemente, em uma perspectiva que dá ênfase ao ethos: "desde que haja enunciação, alguma coisa da ordem do ethos se encontra liberada: por meio de sua fala, um locutor ativa no intérprete a construção de determinada representação de si mesmo" (MAINGUENEAU, 2008b, p. 73).

A noção de ethos, como se sabe, a partir da retórica aristotélica, é a imagem que o destinatário constrói do locutor através da maneira como ele se exprime; trata-se de uma representação elaborada pelo discurso, mas que se apoia em estereótipos historicamente especificados que preexistem ao discurso. Maingueneau (1989, 2005, 2008b) amplia tal noção no quadro da análise do discurso. Enquanto a retórica ligou o ethos à oralidade, o autor

\footnotetext{
4 Sobre a relação entre cena genérica e cenografia, ver Rocha (2013).

5 O termo "tom", como diz o autor, tem a vantagem de valer tanto para o escrito quanto para o oral.
}

propõe que qualquer texto (oral ou escrito) tenha uma "vocalidade" específica, que permite relacioná-la a uma caracterização do corpo do enunciador, não ao corpo do locutor extradiscursivo, que, por meio de seu "tom", atesta o que é dito. Tal proposta afasta a noção de ethos de "um dispositivo retórico, pelo qual o autor 'escolheria' o procedimento mais adequado ao que ele 'quer dizer','(MAINGUENEAU, 2008a, p.93); abordagem "psicologizante" e "voluntarista" que pressupõe um autor dono de seu dizer, que elaboraria a sua escolha em função dos efeitos que pretende produzir sobre seu auditório. Do ponto de vista da $\mathrm{AD}$, "esses efeitos são impostos não pelo enunciador, mas pela formação discursiva" (MAINGUENEAU, 1989, p. 45).

A preocupação do autor ultrapassa, também, o quadro da argumentação: além da persuasão pelos argumentos, a noção de ethos "permite refletir sobre o processo mais geral da adesão dos sujeitos a determinado posicionamento". Processo mais evidente quando se trata de discursos que "devem ganhar um público que está no direito de ignorá-los ou de recusá-los", como a publicidade, a política etc. (MAINGUENEAU, 2008b, p.64), contrariamente ao que acontece com os prescritos no trabalho e as atividades de trabalho.

A legitimação dos discursos não passa somente pela articulação dos conteúdos; ela é sustentada por um enunciador "fiador", cuja "corporalidade", mais ou menos imprecisa, é construída no próprio movimento da leitura. As "ideias" se apresentam através de uma maneira de dizer que é também uma maneira de ser, associadas às representações e normas de "disciplina" do corpo na sociedade: existe um "mundo ético", um universo de comportamentos estereotipados, correntemente associados (cf. MAINGUENEAU, 2008b, p. 146).

A opção de Maingueneau se manifesta por uma concepção mais "encarnada" do ethos, que recobre não apenas a dimensão verbal, mas também características físicas (corporalidade) e psíquicas (caráter), associadas ao fiador, com base em estereótipos, representações sociais coletivas, que a enunciação pode reforçar ou transformar. Dessa forma, a questão do ethos é também um reflexo do "processo mais geral da adesão de sujeitos a uma certa posição discursiva" (MAINGUENEAU, 2005, p. 69).

A incorporação - maneira pela qual o leitor se apropria do ethos - ultrapassa a simples identificação a um fiador, implicando o acesso do leitor a um "mundo ético", que está impregnado no fiador, e ao qual ele dá acesso ao leitor por meio da enunciação. Se o ethos está ligado ao ato de enunciação, não se pode ignorar que o leitor constrói representações do enunciador antes mesmo que ele fale. A essas representações prévias, costuma-se chamar ethos pré-discursivo. Ainda que o leitor nada saiba sobre o enunciador, o simples fato de que um texto pertence 
a um gênero do discurso ou a um certo posicionamento ideológico, ou mesmo ao quadro de uma instituição, induz expectativas em termos de ethos. O ethos de um discurso resulta de uma interação de diversos fatores, ethos prédiscursivo, ethos discursivo (ethos mostrado), mas também de fragmentos do texto em que o enunciador evoca sua própria enunciação (ethos dito) direta ou indiretamente (por meio de metáforas, alusões etc.) ${ }^{6}$.

Adotar o ponto de vista enunciativo-discursivo como o fazemos implica apreender os enunciados como imbricação de um texto e de um lugar social. Mediante as operações enunciativas por meio das quais se institui o discurso, articulam-se a organização textual e a organização institucional, entendida aqui como comunidade discursiva, que o discurso, ao mesmo tempo, pressupõe e estrutura.

O "conteúdo" do discurso aparece como inseparável da maneira como ele administra sua própria emergência, o evento de fala que ele institui. A partir dessa ótica, estudamos as práticas verbais que caracterizam as diferentes situações de trabalho relacionadas a uma determinada comunidade profissional. Privilegiaremos as condições materiais da comunicação, os papéis que ela implica para seus participantes, os contratos que se estabelecem entre eles, seu suporte material, as restrições que pesam sobre a organização textual. Isto porque o "conteúdo", na verdade, não é independente do dispositivo de transmissão; ele implica o conjunto do dispositivo de comunicação, aí incluídas as modalidades de suporte e de transporte dos enunciados que tornam o texto possível.

As falas na/sobre as atividades de trabalho são, ao mesmo tempo, seu produto e a condição de sua identidade. Este fato se traduz no funcionamento enunciativo. Os textos sobre/no trabalho são também o lugar onde se autolegitima a comunidade que produz tais textos, os discursos que circulam no cotidiano de trabalho, as falas, as normas, as renormalizações. A comunidade discursiva é entendida, assim, como a comunidade daqueles que produzem, que fazem com que o discurso circule, que se reúnem em seu nome e nele se reconhecem. "O espaço de enunciação, longe de ser um suporte, um quadro exterior ao discurso, supõe a presença de um grupo específico sociologicamente caracterizável, o qual não é um agrupamento de 'porta-vozes"' (MAINGUENEAU, 1989, p. 54).

Não há, portanto, relação de exterioridade entre o funcionamento do grupo e o funcionamento de seu discurso, sendo preciso pensar desde o início nessa imbricação. Dito de outra forma, é preciso articular as coerções que possibilitam o discurso com as que possibilitam o grupo já que estas duas instâncias são conduzidas pela mesma lógica, isto é, a comunidade discursiva.
Estamos aqui fazendo um deslocamento da noção de comunidade discursiva, postulada por Maingueneau para tratar de discursos fortemente institucionalizados, a fim de tratarmos das comunidades profissionais. E o fazemos a partir do que consideramos uma autorização do próprio autor, em nota de rodapé, em Cenas de Enunciação: esta "noção não está estabilizada em análise do discurso". Ela foi introduzida para insistir sobre o fato de que "os modos de organização dos homens e de seus discursos são indissociáveis". Mais adiante, o próprio autor faz referência à possibilidade de ampliar essa noção para toda a "comunidade de comunicação restrita organizada em torno da produção de discursos [...]. Seus membros partilham de certos modos de vida, de determinadas normas etc." (MAINGUENEAU, 2008b, p. 142-143). Justamente o que temos observado em situação de trabalho.

Outras noções desenvolvidas por Maingueneau, como a de autoria, estão sendo observadas em alguns textos que circulam em situação de trabalho, os quais apresentam pelo menos dois níveis de autoria: um constituído pelos prescritos no trabalho, pelas normas descendentes ${ }^{7}$, que são, por definição, anônimas, consideradas como emanando de uma instituição indivisível, por exemplo, empresas, hospitais etc.; o outro nível, constituído pelas falas, renormalizações ${ }^{8}$ no cotidiano de trabalho. $\mathrm{O}$ contraste entre os textos das normas e o das renormalizações é marcado, linguisticamente, por planos diferentes: no primeiro, os enunciados encontram-se no plano não-embreado, no qual o par eu-você está ausente, e no segundo, os enunciados estão nas primeira e segunda pessoas do discurso, isto é, no plano embreado.

Como se sabe, os enunciados embreados estão ancorados na situação de enunciação e contêm, além de embreantes, outras marcas da presença do enunciador: apreciações, interjeições, exclamações, ordens, interpelação do coenunciador etc. Os enunciados não embreados não são interpretados em relação à situação de enunciação. Procuram construir universos autônomos. Evidentemente, tais enunciados possuem um enunciador e um coenunciador, e são produzidos em um momento e lugar particulares, mas apresentam-se como se estivessem desligados de sua situação de enunciação.

Outra característica desses discursos das normas é o "tom", bastante particular de sua enunciação, caracterizado pela ausência de marcas de interação e de modalizações avaliativas e pelo apagamento de referências reflexivas, traços de um ethos bem tipificado, que não está dissociado de certo "código linguageiro", ou seja, da maneira

\footnotetext{
6 Ver Maingueneau (2005).

7 Tais normas são aquelas que provêm da hierarquia.

8 Ajustamentos que dependem da variabilidade de cada situação.
} 
específica pela qual as diferentes profissões investem na diversidade das línguas naturais. Esses textos, na verdade, não se desenvolvem na compacidade de uma língua, mas através de uma "interlíngua", entendida como o conjunto de línguas e de variedades no interior das línguas acessíveis a um locutor que ocupa determinada posição na sociedade, como um espaço de confronto entre as variedades linguageiras: variedades "internas" (usos de determinada profissão, níveis de linguagem, dialetos...) ou variedades "externas" (idiomas "estrangeiros"). É compreensível que os discursos profissionais mantenham, assim, uma relação essencial com a interlíngua.

Para a AD, no seu enfoque enunciativo-discursivo, os aspectos que estruturam a sociedade podem ser conhecidos por meio de discursos, dentre os quais destacamos aqueles que são produzidos, reproduzidos, transformados e postos a circular em situação de trabalho. Conhecer tais discursos implica buscar apoio na Ergologia, abordagem pluridisciplinar que se apresenta como um modo inovador para abordar a atividade humana em geral e a atividade de trabalho em particular ${ }^{10}$. Desde seu início, o Laboratório Analyse Pluridisciplinaire des Situations de Travail (APST), composto por uma equipe de pesquisadores de diferentes áreas, liderada pelo filósofo Yves Schwartz, tem por objetivo compreender as mudanças em curso nas atividades econômicas ("mutações tecnológicas", transformações das maneiras de produzir, redimensionamento das proporções entre as categorias da população ativa...) por meio da cooperação entre, de um lado, os diversos saberes acadêmicos voltados para o trabalho e os pesquisadores aí envolvidos e, de outro, as experiências, saberes, valores, investidos pelos protagonistas dessas atividades em seu cotidiano de trabalho. Com o avançar das pesquisas, foi ficando cada vez mais claro que "o conceito de atividade - por mais enigmático que seja e o retrabalho que exija -é, sem dúvida nenhuma, o elemento dinâmico de convergência dessas cooperações pluridisciplinares e pluriprofissionais" (SCHWARTZ, 2010, p.21). A abordagem acerca do trabalho - e mais genericamente, da atividade humana - supõe uma troca constantemente renovada entre pesquisadores e atores sociais.

O olhar ergológico exige do pesquisador uma postura de humildade, um "desconforto intelectual", relacionado não só ao fato de que nenhuma disciplina ou ciência permite o conhecimento de um fenômeno em sua

\footnotetext{
9 As noções de código linguageiro e interlíngua já aparecem na obra de Maingueneau $O$ contexto da obra literária, São Paulo: Martins Fontes, 1995.

${ }_{10} \mathrm{Na}$ parte referente à Ergologia, baseei-me, fundamentalmente, no livro Trabalho e ergologia: conversas sobre atividade humana (2010), no "Manifesto por um ergoengajamento" (2011) e no minicurso "Como pensar as mudanças do trabalho? Contribuições da Ergologia", ministrado por Schwartz no LAEL, em abril de 2012.
}

totalidade, mas também à constatação de que "a atividade de trabalho no essencial não se vê" (SCHWARTZ, 2011, p. 134). Partindo das reflexões explicitadas até o momento, recorro aqui à metáfora do triângulo por meio da qual Schwartz se propõe a explicitar sua concepção de trabalho como o encontro entre normas, renormalizações e debate de valores.

Como espécie viva, para sobreviver e viver, o ser humano deve se conformar a normas de todos os tipos criadas na e pela história. Com a evolução das civilizações, a codificação das normas ganha cada vez mais terreno. Tais normas designadas por Schwartz de "normas antecedentes" se justificam porque decorrem de um patrimônio universal da humanidade (concepção de inovações, técnicas, de programas de informática, manuais de utilização, regras de segurança etc.) e das capitalizações da experiência histórica humana, abarcando, portanto, as constituições, leis, regulamentos que progressivamente construíram as sociedades de direito. Em situação de trabalho, as normas antecedentes enquadram, antecipam, predeterminam as atividades a serem realizadas e apresentam-se como uma combinação inextricável de conquistas e riscos, tanto facilitadoras quanto opressoras da vida social. Facilitadoras porque tendem a unificar os coletivos de trabalho, a tornar possível a vida em conjunto; opressoras, porque podem funcionar como ferramentas na construção de relações de força a fim de garantir poder, dominação, vantagens adquiridas, instrumentos de exploração industrial, jurídica, econômica (cf. SCHWARTZ, 2011, p. 135-136).

A norma é, portanto, necessária. É uma conquista de toda a sociedade humana, mas ela comporta também um risco, aquele de ser considerada como um fim em si, como um poder de antecipação absoluto, como uma tentativa de simplificar a atividade humana, ou seja, de prepará-la de tal forma pelos outros de modo que os trabalhadores, aqueles que deveriam executá-la, não teriam de pensar. Mas "a atividade sempre se convida, com sua tessitura individual e coletiva, a debates de normas" (SCHWARTZ, 2011, p. 137). Antecipar os atos humanos a partir de normas antecedentes codificadas e conhecidas é impossível e invivível, conforme os vários balanços posteriores ao taylorismo. Impossível porque a tendência à renormalização é um fato universal. Invivível porque nociva à saúde. Viver em saúde pressupõe nunca se tornar puro instrumento de injunções, de trajetórias, previamente pensadas pelo meio, previamente pensadas por outros.

Frente a uma pane, diante de um vazio jurídico ou regulamentar, diante de um caso social particularmente complicado, cada um tratará esses vazios de normas recorrendo a um universo de recursos pessoais, hierarquizado por seu conjunto de valores do momento. 
Isso se dando, sua escolha quanto à forma de lidar com a situação irá se inscrever na história do meio técnico e social, irá fabricar novas microjurisprudências que fazem história, desestabilizam o protocolo, obrigando-o a se colocar em manutenção. A necessidade de recriar as normas, de renormalizar como oportunidade, mesmo minúscula, para a saúde de cada humano no trabalho saúde que remete à singularidade de sua história - reforça a impossível estandartização do agir (cf. SCHWARTZ, 2011, p. 138-139).

Partindo das reflexões explicitadas até o momento, recupero três proposições que se poderia dizer são especificamente ergológicas e caracterizam a atividade humana em geral e a de trabalho em particular. De acordo com a primeira proposição, a distância entre as normas, as prescrições e a atividade realizada é universal. Essa distância se explica em decorrência da variabilidade das situações de atividade de trabalho e também do que significa viver no trabalho para cada um. Qualquer que seja a situação, haverá sempre uma distância entre o que se pensa acerca do trabalho (seja o que outros pensam, seja o que nós mesmos pensamos) e a realidade desse trabalho. Os/As trabalhadores/as sempre reorganizam permanentemente seus postos de trabalho (cf. SCHWARTZ, 2010, p. 42).

A segunda proposição - o conteúdo da distância é sempre parcialmente ressingularizado. Sabemos que sempre existirá uma distância, mas que não poderemos jamais prevê-la. "Essa distância só será explicitada caso se vá a campo para ver, e caso se aprenda com o que se vê, inclusive discutindo com a pessoa que trabalha; então, essa distância é sempre singular" (SCHWARTZ, 2010, p.43). Portanto, uma proposição universal - há sempre uma distância entre as normas e a atividade - é seguida de uma segunda proposição: essa distância é sempre parcialmente singular. Podem-se levantar hipóteses: existem regularidades, tendências, mas se se quer ir aos detalhes, é preciso tentar compreender que defasagem é essa. "A distância está sempre a ser introduzida na história porque se trata sempre de uma história particular, a história de uma operadora, de um coletivo, com suas características morfológicas, psíquicas, culturais" (SCHWARTZ, 2010, p. 43).

Finalmente, a terceira proposição traz a questão do debate de valores na atividade de trabalho. A racionalidade de normas que antecipam todo agir social não dissipa nem torna inútil a obrigação feita a cada trabalhador/a de repensar, no seu íntimo, suas escolhas na vida e no trabalho. Obrigação feita de escolhas, portanto, de se situar, de uma maneira ou de outra, em um mundo de valores, de escolha. Nesse agir, nada pode ser pura aplicação do que se tinha pensado antes. A atividade de trabalho, entre todas as outras atividades humanas com as quais ela se comunica, não tem, de modo algum, o privilégio dessa dimensão "dramática". Mas, sem dúvida, ela a toca diretamente, expressa, talvez melhor do que toda outra forma do agir humano, a obrigação inelutável de escolhas que remetem a pessoa a ela mesma, escolhas estas que fazem história. Fazem história porque criam uma situação nova que nenhuma racionalidade antecedente teria podido predeterminar.

Retomo aqui a frase de Schwartz há pouco mencionada: "a atividade de trabalho no essencial não se vê". Percebem-se, de um lado, seus resultados, seus meios: produtos, bens, serviços, e de outro, ferramentas, máquinas, organogramas, programas, documentos.... Transcrevo sua pergunta: "Pode-se, então, considerar a atividade a partir de meios e produtos visíveis, quantificáveis do trabalho?" (SCHWARTZ, 2011, p. 134). E sintetizo sua resposta. A avaliação do trabalho apenas pelos "resultados" não deixa ver as renormalizações, as múltiplas "dramáticas" da atividade. "Essas dramáticas são fontes de eficácia, mas [...] são inseparáveis de certos valores de vida e de saúde, de modo que não se pode mergulhá-las na invisibilidade" (SCHWARTZ, 2011, p. 134-135). Falar da dimensão dramática da atividade não significa que cada agir seja semeado de dramas, significa que nada pode ser mecânico. "Toda avaliação do trabalho puramente quantitativa oculta esse contingente de microdramáticas" (SCHWARTZ, 2011, p. 135). Julgar, por exemplo, a qualidade dos serviços dos/as agentes de uma central de atendimento, por telefone ou por chat, a partir de um número de comunicações tratadas por unidades de tempo e por estruturas linguísticas préformatadas significa suscitar nesses/as operadores/as a vontade, às vezes obrigação, de driblar o/a cliente, ou o/a supervisor/a, de contornar seus próprios problemas, evitar entrar com suas próprias dramáticas (SOUZA-E-SILVA e ROCHA, 1999; ALGODOAL, 2002; BOUTET, 2008; ANJOS, 2011).

Há sempre valores em jogo na atividade. $\mathrm{O}$ trabalho manifesta seus limites quando colocado em prática. Se se aceita que há sempre distância entre as normas e o trabalho realizado, isto quer dizer que as pessoas fazem escolhas, conscientes ou não. As escolhas se fazem em função de critérios - e, portanto, em função de valores que orientam essas escolhas. E então existem debates denominados por Schwartz de "debate de normas" / "debate de valores", os quais geralmente não são vistos, mas vê-los é fundamental no trabalho. "Há debate de normas no interior da menor atividade de trabalho, a mais ínfima" (SCHWARTZ, 2010, p.45). Esses debates são, ao mesmo tempo, debates de valores consigo mesmo e de ordem social. Os primeiros são ligados ao que o filósofo chama de "economia" ou "racionalidade do corpo". Economizar-se, economizar a fadiga, manter o ritmo. Isso faz parte dos valores em jogo. 
Os segundos referem-se ao "bem viver juntos", debates de valores que atuam como um acordo permanente entre o global e o microscópico. Se se luta, mesmo no infinitamente pequeno, nas minúcias para tornar vivível a vida dos colegas de trabalho, do coletivo de trabalho, é porque o "viver juntos tem um certo valor. E se ignoramos esses debates de valores não compreendemos o trabalho" (SCHWARTZ, 2010, p. 45-46).

\section{O paradigma indiciário como modelo epistemológico: um momento de rara luminosidade ${ }^{11}$}

As raízes de tal paradigma remontam às origens da humanidade, quando, por motivos de sobrevivência, o homem desenvolveu algumas atividades, como a de caçar, que exigia atenção aos detalhes, às pistas, quase imperceptíveis, deixadas pela presa. De algum tempo para cá, o paradigma indiciário passou a ser um dos principais modelos de análise das ciências médicas, da crítica de arte, da psicanálise e da investigação policial (cf. GINZBURG, 1989).

Em todas essas áreas, a leitura detalhada e a observação meticulosa e rigorosa de pequenos indícios podem levar à construção de hipóteses que, após serem testadas, conduzirão a um determinado resultado. Na medicina, por exemplo, o estudo detalhado de alguns sintomas, aparentemente superficiais, permite diagnosticar várias doenças. O paradigma indiciário supõe a existência de um rigor flexível e elástico. Flexível porque não exige o estabelecimento de uma verdade única, universal e inquestionável; elástico porque não prescinde do rigor, não abre mão da interpretação. Portanto, nega a existência de uma realidade diretamente cognoscível e propõe a análise dos indícios como forma de aceder a um certo conhecimento.

Mais precisamente, tal modelo epistemológico emergiu no âmbito das ciências humanas no final do século XIX substituindo os modelos de análises das ciências ditas naturais focadas na observação do geral, a fim de alcançar uma totalidade. O paradigma indiciário, ao contrário, tem sido responsável, principalmente ao longo dos últimos dois séculos, por uma verdadeira transformação no olhar do pesquisador, voltado para o detalhe, para o dado aparentemente insignificante.

Vê-se, portanto, a valorização de pistas supostamente sem importância ou cuja importância limitar-se-ia, aparentemente, a aspectos mais visíveis e factuais e não a interpretações de relevância social. Nesse sentido, o paradigma indiciário é inovador como método investigativo não apenas pelo fato de dar relevo a sinais pouco

\footnotetext{
${ }^{11}$ Essa caracterização foi extraída de referência à obra de Ginzburg, Mitos, emblemas, sinais, feita por Laura de Mello e Souza na orelha do livro em questão.
}

visíveis, mas, principalmente, por ver nesses sinais grandes descobertas. É justamente a possibilidade de decifrar, a partir de minúsculas pistas, um grande crime que apaixona os leitores dos clássicos policiais do detetive Sherlock Holmes (cf. GINZBURG, 1989).

A ideia de uma investigação feita por meio de diferentes etapas nas quais os indícios são aparentemente "insignificantes" vão dando acesso às camadas menos visíveis do fenômeno pesquisado, produzindo assim uma observação cada vez mais acurada acerca de um determinado acontecimento, o que permite uma aproximação, guardadas as devidas proporções, entre o paradigma indiciário e a noção de atividade do trabalho, segundo a ótica schwartziana: a atividade de trabalho no essencial não se vê.

$\mathrm{O}$ trabalho de quem analisa indícios é encontrar, por meio da observação atenta de pequenos detalhes, sinais das consequências menos visíveis das diferentes atividades de trabalho e das várias possibilidades de interpretação de um texto. Nega-se aqui o tipo de interpretação postulado pela Análise de Conteúdo, conforme artigo de Rocha e Deusdará neste volume, referente aos limites de uma abordagem conteudista das práticas de linguagem.

A relação entre o paradigma indiciário e Gênese dos discursos pode ser percebida por meio dos indícios encontrados por Maingueneau quando da análise dos discursos religiosos. Estudando semas que constituem o modelo dos discursos jansenista e humanista devoto, o autor encontra uma série de pistas e/ou indícios que se manifestam por meio do conjunto de coerções que regem os diferentes planos do discurso. As diversas pesquisas desenvolvidas pelo autor privilegiam reflexões sobre conceitos e métodos, que permitam ligar as grandes hipóteses teóricas à infinita diversidade de manifestações da atividade discursiva.

Temos aqui, adaptando princípios da abordagem ergológica, um dispositivo dinâmico de três polos interrelacionados: o discursivo, o ergológico e o indiciário, os quais terão êxito se chegarem a produzir zonas de aprofundamento comuns quanto aos projetos de cada um em termos de produção de saberes e de atividades.

\section{Referências}

ALGODOAL, Maria Juliana A. As práticas de linguagem em situações de trabalho de operadores de telemarketing ativo de uma editora. 2002. 201. fls. Tese (Doutorado em Linguística Aplicada e Estudos da Linguagem) - Pontifícia Universidade Católica do São Paulo, São Paulo, 2002.

ANJOS, Joelma S.T. dos. Práticas de linguagem em situação de trabalho - chat: um novo gênero digital. 2011. 158. fls. Dissertação (Mestrado em Linguística Aplicada e Estudos da Linguagem) - Pontifícia Universidade Católica do São Paulo, São Paulo, 2011. 
BOUTET, Josiane. La vie verbale au travail. Des manufactures aux centres d'appels. Toulouse: Octarès, 2008.

DANIELLOU, François (Dir.). L'ergonomie enquête de ses principes: débats épistémologiques. Toulouse: Octarès, 1996.

GINZBURG, Carlo. Sinais: Raízes de um paradigma indiciário. In: Mitos, emblemas, sinais. Tradução de Federico Carotti. São Paulo: Companhia das Letras, 1989. p. 143-179. [Mitti emblemi spie: morfologia e storia. Torino, Giulio Einaudi, 1986].

KRIEG-PLANGE, Alice. A noção de fórmula em análise do discurso - quadro teórico e metodológico. Tradução de Luciana Salazar Salgado e Sírio Possenti. São Paulo: Parábola, 2010. [ La notion de "formule" en analyse du discours - cadre théorique et méthodologique. Paris: Presses Universitaires de FrancheCompté, 2009].

MAINGUENEAU, Dominique. Análise de textos de comunicação. Tradução de M. Cecília de Souza e Silva e Décio Rocha. 6. ed. ampliada. São Paulo: Cortez, 2013. [Analyser les textes de communication. 2e. édition. Paris: Armand Colin, 2007].

MAINGUENEAU, Dominique. Gênese dos discursos. Tradução Sírio Possenti. São Paulo: Parábola. 2008a [Genèses du discours. Paris: Pierre Mardaga, 1984].

MAINGUENEAU, Dominique. Cenas da enunciação. Organização de Sírio Possenti e Maria Cecília Pérez de Souza e Silva. São Paulo: Parábola, 2008b.

MAINGUENEAU, Dominique. Ethos, cenografia, incorporação. In: AMOSSY, R. (Org.). Imagens de si no discurso: a construção do ethos. São Paulo: Contexto, 2005. p.69-92.

MAINGUENEAU, Dominique. Análise de textos de comunicação. Tradução M. Cecília de Souza e Silva e Décio Rocha. 1. ed. São Paulo: Cortez, 2001. [Analyser les textes de communication. Paris: Dunod, 1998].

MAINGUENEAU, Dominique. Novas tendências em Análise do Discurso. Tradução Freda Indursky. Campinas: Pontes, 1989. [Nouvelles tendances en analyse du discours. Paris : Hachette, 1987].
POSSENTI, Sírio. Teoria do discurso: um caso de múltiplas rupturas. In: MUSSALIM, Fernanda; BENTES, Anna Cristina (Org.). Introdução à Linguística: fundamentos epistemológicos, São Paulo: Cortez, 2004. v. 3, p. 353-392.

ROCHA Décio. Cartografias em Análise do Discurso: rearticulando as noções de gênero e cenografia. DELTA. Documentação de Estudos em Linguística Teórica e Aplicada, v. 29, p. 135-159, 2013.

SCHWARTZ, Yves. Manifesto por um ergoengajamento. In: BENDASSOLLI, Pedro F.; SOBOLL, Lis. A.P. (Org.). Clínicas do trabalho: novas perspectivas para compreensão do trabalho na atualidade. São Paulo: Atlas, 2011. p. 132-166. [L'activités en dialogues: entretiens sur l'activité humaine II. Toulouse: Octarès, 2009].

SCHWARTZ, Yves. Introdução I; Introdução II; Reflexão em torno de um exemplo de trabalho operário. In: SCHWARTZ, Yves; DURRIVE, Louis (Org.). Trabalho e ergologia: conversas sobre atividade humana. 2. ed. revista e ampliada. Niterói: EDUFF, 2010. p. 19-20; p.21-22; p.37-46. [Travail et ergologie: entretiens sur l'activité humaine. Toulouse: Octarès, 2003].

SCHWARTZ, Yves. L'homme, le marché, la cité. In: C'est quoi le travail. Paris: Autrement. 1997. p. 110-127.

SILVA, Edvânia G. Os (des)encontros da fé: análise interdiscursiva de dois movimentos da Igreja Católica. 2006. $287 \mathrm{fls}$. Tese (Doutorado em Linguística) - Universidade Estadual de Campinas, 2006.

SOUZA-E-SILVA, Cecília \& ROCHA, Décio. A linguagem nas relações de trabalho: a fala da operadora de telemarketing. Anais do XXVIII do Seminário do Grupo de Estudos Linguísticos do Estado de São Paulo. São José do Rio Preto: Editora da UNESP, 1999. p. 296-301.

Recebido: 04 de março de 2014

Aprovado: 11 de abril de 2014

Contato: cecilinh@uol.com.br 